\title{
Numerical Based Approach for Predicting the Response of Flexible Risers Under Oscillatory Flows at Low Re and KC Numbers
}

\author{
Enfoque Numérico para Predecir la Respuesta de Tubos Flexibles Bajo Flujos \\ Oscilatorios con Bajos Números De Re Y KC
}

\author{
M. C. Valencia-Cárdenas iD, C. A. Riveros-Jerez iD
}

\begin{abstract}
Flexible riser response prediction relies on semiempirical models hindered by limitations due experimental data scarcity for particular modelling considerations. This paper presents a numerical-based approach for predicting the flexible riser response under oscillatory flows. A single freedom degree spring-mass-damper system is employed with the mass allowed to move in cross-flow direction. To discretize the Navier-Stokes equations the Finite Volume Method is used. To analyze the flow patterns in each regime the cylinder oscillating period is executed for long time. A bi-dimensional model is setting up using OpenFOAM simulations. Flow behavior, hydrodynamic forces and frequencies were analyzed for Reynolds values between 401000 using a $K C$ number 7,9. For Reynolds less than 300 the behavior is in agreement with the literature. For Reynolds 300 or higher, some discrepancies appear in the system dynamics. The numerical results obtained from the numerical approach shows good agreement with experimental data collected from a flexible riser model.
\end{abstract}

Index Terms - Flexible riser, Keulegan-Carpenter number, Numerical Simulation, Oscillating Flow, Vortex Dynamics

Resumen- La predicción de respuesta en tuberías verticales flexibles se basa en modelos semiempíricos limitados por escasez de datos experimentales para modelados particulares. Este artículo presenta un enfoque numérico para predecir la respuesta de tuberías verticales flexibles en flujos oscilatorios. Se implementa un grado de libertad en un sistema de masa-resorte amortiguado, con la masa habilitada para moverse en la dirección transversal al flujo. Las ecuaciones de Navier-Stokes son discretizadas empleando el Método de Volúmenes Finitos. Los patrones de flujo en cada régimen son analizados en períodos de oscilación extensos. Se emplea un modelo bidimensional simulado en OpenFOAM. Se analiza el comportamiento del flujo, fuerzas hidrodinámicas y frecuencias para los valores de Reynolds entre 40 y 1000 utilizando $K C$ 7, 9. Para Reynolds, inferiores a 300, el comportamiento del modelo está de acuerdo con la literatura. Para valores de Reynolds 300 o más, algunas discrepancias aparecen en la dinámica del sistema. Los resultados numéricos obtenidos a

This manuscript was sent on November 30, 2018 and accepted on March 15, 2019

M. C. Valencia-Cárdenas is with the School of Engineering, Universidad de Antioquia, Antioquia, CO 054030 Colombia (e-mail: mcatalina.valencia@udea.edu.co) partir del enfoque numérico propuesto concuerdan con los datos experimentales recopilados en un modelo de tubería vertical flexible

Palabras claves- Tuberías Verticales Flexibles, Número de Keulegan-Carpenter, Simulación Numérica, Flujo Oscilatorio, Dinámica de Vórtices.

\section{INTRODUCTION}

$\mathrm{T}$ he movement around a cylinder is still an issue of great interest in fluid dynamics because several key engineering structures, such as marine cables, riser tubes, pipelines, submarines, and off-shore structures among others, are affected by the accumulated stress. These applications are exposed to an external variable velocity flow that causes vortex shedding downstream the cylinder, an unsteady unwanted phenomenon. The frequency at which the vortices are shear is known as vortex shedding frequencies; a regular pattern of vortices induces fluctuating lift and drag forces on the cylinder [1]. Additionally, to the cylinder structural properties and the incoming flow characteristics, those vortices can exert a significant dynamic stress, increasing the damage accumulation and eventually causing structural failure.

In some situations, the current relative velocity may be nonstationary, due either to structural movement or to oscillations in the incoming flow itself [2]. The structural movement is a very common phenomenon in flexible cylindrical systems but there is still a limitation to accurately predict the response of these structures because most of the prediction models rely heavily on large experimental databases. In addition, flexible and light materials have been developing for marine applications leading to slender structures with low mass ratios (defined as the ratio of mass of the cylindrical system per unit length to the mass of displaced water). Thorsen et al. [2]

C. A. Riveros-Jerez is with the School of Engineering, Universidad de Antioquia, Antioquia, CO 050010 Colombia (e-mail: carlos.riveros@udea.edu.co) 
presents an improved semi-empirical model for predicting the risers response, the model provides realistic results in terms of frequency content, amplitude of vibration, and demonstrated that the maximum amplitude for cross flow oscillation is smaller for the high mass ratio case. Bowen Fu and Decheng Wan [3] presented a numerical model based solely on the computational fluid dynamics method using the strip theory, and showed that it is possible to rely only on numerical simulations for risers response prediction, overcoming the limitations of large databases used by most current software for predicting the response of risers; those authors use a mass ratio of 1.53 and $K C$ numbers ranging from 21 to 184 .

A great deal of works about oscillatory flow around a fixed cylinder have been done (e.g. [4], [5], [6], [7], [8], [9]). It has been found that as flow period increases, the flow behavior change, and the number of vortices shed from the cylinder increases with the Keulegan-Carpenter $(K C)$ number increasing. This number is defined as $K C=U_{m} T / D$, where $U_{m}$ is the amplitude of the oscillatory flow velocity, $T$ is the oscillatory flow period and $D$ is the diameter of the cylinder. In this way, the $K C$ value determines the sinusoidal oscillatory flow characteristics and hence the hydrodynamics forces generated by vortices around the cylinder. When $K C$ is small enough, the cylinder's surface boundary-layer is laminar and two-dimensional, but as the $K C$ increases it will become unstable and three-dimensional [10].

Experimental work allowed to visualize the flow conduct for $K C$ numbers from 4 to 30 [5], [11]. The vortex pairs numbers shed during each half of a flow period allows to classify the oscillatory flow around a cylinder as transverse street $7<$ $K C<13$, single pair $13<K C<15$, double pair $15<K C<$ 24 , three pairs $24<K C<32$ and four pairs $32<K C<40$ vortex shedding regimes. Also, for each vortex shedding regime the relationship between vortex motions and time-dependent lift-force variations have been described [12]. Although, extensive study of the vertical motion types produced when a cylinder oscillates in a resting fluid has been made [13]. The Tatsuno and Bearman's [13] experiment and modelling differs from Govardhan and Williamson [12] by the force vibration condition and free vibration respectively, a very close correspondence between these flows has been described [14].

With the available data accumulation, heavy influences of Reynolds number on the cylinder maximum response have been demonstrated by Govardhan and Williamson [12] and Klamo et al. [15]. Both experimental and computational studies use a very small mass ratio $\left(m^{*} \xi\right)$ or zero for damping respectively. These studies showed that the Reynolds number becomes crucial in the transition regimen and many authors have been researching its influence until a value of 500, considering a fixed value for $K C$ ( [16], [17], [18], [19], [20], [21], [22], [23]). Tatsuno and Bearman [13] analyzed $1.6<K C<15$ and $5<$ $\beta<160\left(\beta=\operatorname{Re} / K C=D^{2} / v T\right.$, where $v$ is the kinematic viscosity and Reynolds number is $R e=U_{m} D / v$ ), including three dimensional features, provided the identification of eight regimes denoted from A to G, as show in Fig. 1 in a plane $\left(K C, R_{e}\right)$. This classification has become the standard description for the associated flow regimes. The regimen A corresponds to the Williamson`s symmetrical regimen [5] , that is also similar to Regime B but with an axial direction threedimensional structure. Regime C corresponds to vortices of opposite rotation senses in the same fashion of a Von Kármán vortex street. Regime D exhibits a symmetrical V-pattern around the transverse axis, very similar to regime $\mathrm{E}$, however here the V-pattern changes intermittently its direction from one side to the other. Regime F describes the Williamson`s double pair regime [5], whereas the Williamson`s transverse street is similar to Regime G [5]. Finally, the Tatsuno and Bearman [13] regimen classification suggest that a $K C$ such as 7,9 that crosses five different regimens, can be assumed as critical and important to be studied.

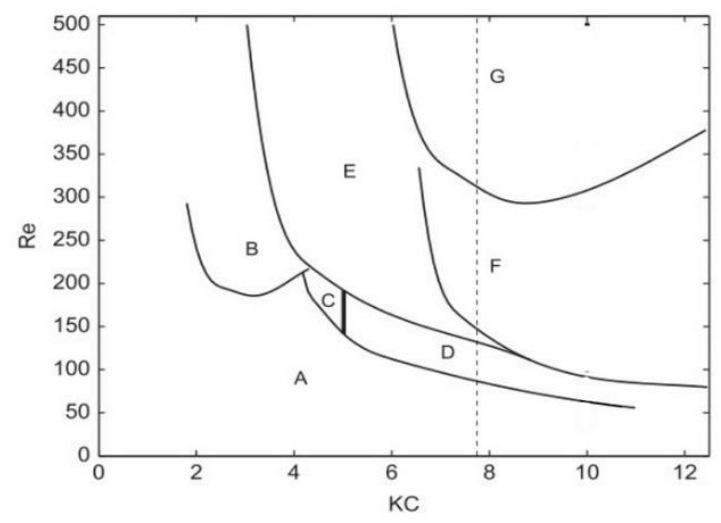

Fig. 1. Classification of flow regimens A to G, identify by Tatsuno and Bearman [13].

This study describes and discusses the oscillating fluid flow effect around a cylinder under the influence of a fixed $K C(7,9)$ and $R e$ between 40 and 1000, considering lower mass ratio and covering the most Tatsuno and Bearman regimes (A, D, E, F and $\mathrm{G}$, see Fig. 1). The cylinder oscillating period is implemented for a long time (more than fifty cycles) in order to analyze the flow patterns in each regime. A single degree of freedom system with a spring-mass-damper is implemented, where the mass is allowed to move only in cross-flow direction. To discretize the transport equations, the Finite Volume Method (FVM) is used and to resolve the pressure-velocity linkage, an iterative solution strategy SIMPLEC algorithm for transient problems is used. Moreover, a bi-dimensional model is established using OpenFOAM simulations and employing a single desktop computer. The results presented here consider an experimental validation by Riveros et al. [24] in order to demonstrate the use of numerical based approaches to predict the response of flexible risers.

In what follows, section 2 presents the numerical method description with the respective equations modeling, parameters taking account, computational domain and boundary conditions. The section 3 provides the procedure for model validation. Vortices behavior descriptions and the time history of the drag and lift forces estimating when Reynolds increases are present in section 4. Likewise, this section put forward a discussion of the flow characterization according to the transitions between regimes established for different intervals 
of Reynolds values. In addition, the results are compared with experimental data in this section. A study summary is presented in section 5.

\section{NUMERICAL METHOD}

This section briefly describes the precisions of the main parameters and numerical method implemented in this study.

\section{A. Governing equations and other parameters}

To model the vortex generation around a structure, commonly a sinusoidal oscillatory flow is considered to represent a realistic phenomenon representation. The flow in the longitudinal direction is given by:

$U_{1}(t)=U_{m} \sin (2 \pi t / T)$

The oscillating flow considered is controlled by 40, 100, 150, 200, 250, 300, 500 and 1000 as Reynolds numbers and 7,9 as Keulegan Carpenter number, so eight different regimens were simulated. Other parameters (mass, damping, reduced velocity) are set up to allow the cylinder movement.

The mass ratio corresponds to $m^{*}=m / m_{d}$, where $m$ represents the cylinder mass and $m_{d}$ the displaced fluid mass. The structural damping ratio is defined as $\zeta=c / 2 \sqrt{\mathrm{km}}$, where $c$ is the structural damping and $k$ is the stiffness of the spring. Finally, reduced velocity is determined as $V_{r}=$ $U_{m} /\left(f_{n w} D\right)$, where $f_{n w}$ represents the cylinder natural frequency measured in water.

To solve the two-dimensional incompressible Navier-Stokes equations, the flow evolution is computed by

$$
\begin{aligned}
& \operatorname{div}(\boldsymbol{u})=0 \\
& \frac{\partial u}{\partial t}+\boldsymbol{u} \cdot \nabla \boldsymbol{u}=-\frac{1}{\rho} \nabla p+\frac{\mu}{\rho} \nabla^{2} \boldsymbol{u}
\end{aligned}
$$

Where $\boldsymbol{u}$ and $p$ represent the velocity and pressure fields in the fluid.

A discretized form of equation (2) must be defined at a nodal point placed within each control volume in order to solve the problem. OpenFOAM, an open source solver, is used to solve the governing equations selecting adequate solution schemes in order to achieve reliable results. To reach it, a second-order central difference scheme is used for the convection and diffusion terms. A stable and accurate simulation is obtained by choosing an implicit second-order scheme for temporal discretization. For the numerical procedure in the simulation, to improve the pressure and velocity coupling, the PIMPLE algorithm is utilized [25].

The structure is allowed to move only perpendicularly to the flow direction. To apply the transport equations to the inertial system, time to time and according to the cylinder movement, the numerical grid is moved and adjusted. For that reason, a mesh dynamic motion solver is implemented in the model, where the cylinder is constrained to only move along " $y$ " and cannot rotate. Finally, the total force per unit length by a stationary cylinder under an oscillatory flow $F_{\text {osc }}$ is known as Morison's equation [26], written as:

$F_{\text {osc }}(t)=\rho C_{m} \frac{\pi}{4} D^{2} \dot{U}(t)+\frac{1}{2} \rho C_{D} D|U(t)| U(t)$

Where $\rho$ represents the fluid density, $C_{m}$ the inertia coefficient and $C_{D}$ the drag coefficient. The last two are functions of $R_{e}$ and $K C$.

\section{B. Computational domain}

The computational domain is a cylinder in a channel represented using two-dimensional numerical simulations as shown in Fig. 2. The cylinder is represented as a circle with diameter $D$ submersed in an incompressible fluid, represented here as a rectangular flow domain. As the simulation begins, the center body is located at the center of the coordinate's axis, $10 \mathrm{D}$ from the horizontal walls and $20 \mathrm{D}$ from the vertical walls. The domain areas around the cylinder, where the vortices are shed, contains a higher cell density in order to obtain a better resolution. This region is shaped by four arcs whose radius equal $2.5 \sqrt{2} D$.

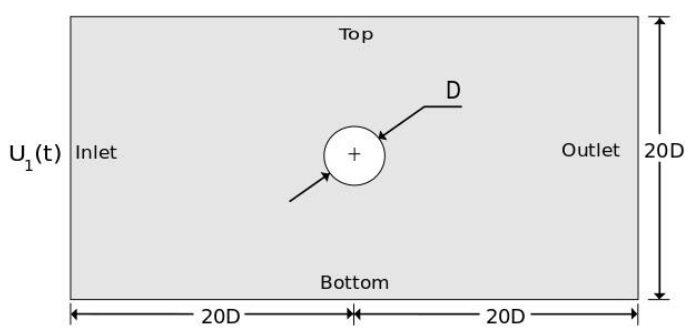

Fig. 2. Sketch of oscillating flow around circular cylinder

To guarantee the smallest numerical errors, it is necessary to proof the meshing independently. The test is developed from a course mesh established, using a non-dimensional time step $U_{1} \Delta_{t} / D=0,1$ (where $\Delta_{t}$ is time step) as sufficient condition to ensure coefficients with three significant digits [27]. Then, the mesh is refined consecutively and the time step is determined from the Courant number $\left(c_{o}\right)$ expression, $c_{o}=\left|U_{1}\right| \Delta_{t} / \Delta_{x}$ where $\Delta_{x}$ is the smaller cell size in the velocity direction and $c_{o}$ is defined as 0.2 [28]. Finally, the appropriate mesh is selected considering the fitting between results and literature and the tradeoff between precision and computational cost.

\section{Boundary conditions}

To carry out the time-dependent simulation, boundary conditions are imposed at each time step. An oscillating velocity is given in the inlet for $\mathrm{x}$-direction only by (1). The oscillatory flow velocity amplitude changes for every Reynolds number.

Because the vertical walls are isolated, a zero gradient patch is assigned to the outlet boundary for the velocity field. To guarantee that the cylinder can move in the y-line, the so-called movingWallVelocity provided by OpenFOAM is assumed as a boundary condition of velocity. This means that the boundary is allowed to move. Slip plane are used in the top and bottom of 
the domain to indicate that there are no physical walls in these borders, so viscous effects on the border are negligible. At the inlet domain and at the cylinder border, zero gradient is assumed. A 0 fixed value is assigned at the outlet pressure field. Finally, the boundary condition of the front and back side of the domain is set as empty since the flow is simulated as two dimensional.

\section{MODEL VALIDATION}

In order to guarantee an accurate solution, the model is setting up at values of Reynolds and Keulegan Carpenter well studied in the literature (e.g. [27], [29], [22], [30]). In this way, $R e=200$ and $K C=10$ in an oscillating fluid flow passing around the circular cylinder were selected. For the mass spring system, the parameters selected are mass ratio $m *$ equal to $4 / \pi$, the damping ratio $\zeta$ equal to 0.01 and reduce velocity $V_{r}=5$. Fig. 3 shows the computational mesh comprising 15600 cells and 31720 points stablished after refined the mesh looking for a good resolution. A $20 \%$ expansion ratio is used to refine the cells near the cylinder. The minimum mesh radius size is $0.006 \mathrm{D}$.

The drag and lift coefficients time history and the Strouhal number are analyzed, considering 20 vortex shedding periods once the periodic flow is stablished. These values have been compared with published results ( [22], [30], [31]) and shown in Table I.

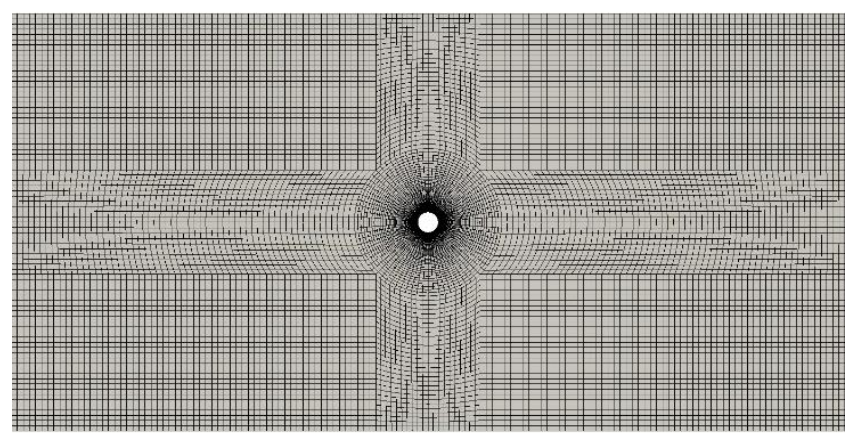

Fig. 3. Computational mesh domain used for the simulation around the cylinder

The drag coefficient (mean value of the in-line nondimensionalized force) and the Strouhal number, $S_{t}=$ $f_{v} D / U_{m}$, are obtained from the frequency of vortex shedding $f_{v}$, which is calculated with the period measured from velocity time history. At $R e=200$ and $K C=10, \bar{C}_{D}$ is equal to 1.331 and $S_{t}$ is equal to 0.192 , meaning that the vortex natural frequency shedding is $f_{0}=0.192$. Results are in good agreement with those published in the literature (see Table I).

TABLE I.

Comparison of drag force coefficient $(\bar{x}=1,307,95 \%$ CI $[1.281,1.332])$ and Strouhal number $(\bar{x}=0,193,95 \%$ CI $[0.187,0.198])$ at $R e=200$ and $K C=$

\begin{tabular}{lcc}
\multicolumn{1}{c}{10} & & \\
\hline & $\bar{C}_{D}$ & $S_{t}$ \\
\hline Guilmineau and Queutey (2002) & 1.286 & 0.195 \\
Cao et al. $(2010)$ & 1.300 & 0.186 \\
Cao and Li (2015) & 1.343 & 0.191 \\
Present work & 1.331 & 0.192 \\
\hline
\end{tabular}

Additional support is given by the good agreement of the numerical based approach presented in this paper with experimental validation data provided by Riveros et al. [24] and discussed below.

\section{RESULTS AND DISCUSSIONS}

The results of direct numerical simulation are present in this section considering the effect of $K C=7,9$ and Reynolds values equals to $40,100,150,200,250,300,500$ and 1000. In this work, the regimes are defined from the flow structure and force behavior.

\section{A. Drag and lift force coefficients}

Drag and lift coefficients time histories in an oscillating flow are estimated using force coefficients function library by OpenFOAM. Vortex shedding frequencies and Strouhal numbers obtained for different Reynolds values are shown in Fig. 4. The time history frequencies are verified for both drag and lift coefficients in order to obtain the vortex shedding frequency $\left(f_{v}\right)$, using the Fast Fourier Transform method (FFT) [29].

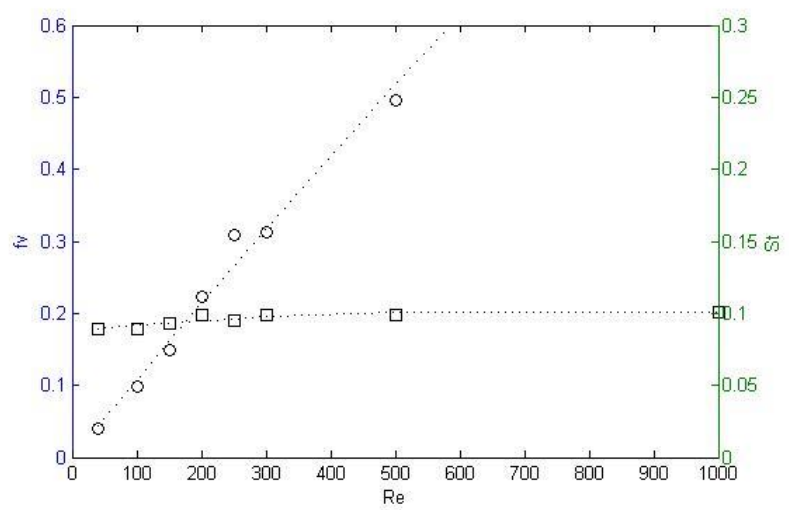

Fig. 4. Vortex shedding frequencies (circle) and Strouhal numbers (square) by Reynolds number

The dominant frequency corresponds to the oscillating frequency. The results are in agreed with the coefficients behavior shown in Figs. 5-6. The drag force coefficients for $R e=200$ and $R e=1000$ are shown in Fig. 5. Notice that both figures do not present significant change period along the time.

Conversely, the amplitude presents some variations, specially at higher Reynolds values. The pase lag between the oscillating flow and drag coefficient for $R e=200$ is about $40^{\circ}$ and the behavior is sinusoidal as the oscillatory flow, with constant period along the time. On the other hand, for $R e=$ 1000 the pase lag is about $20^{\circ}$ as show in Fig. 5(b). The variation of the peaks shape in Fig. 5(b) is related to the pressure distribution asymmetry in the flow direction. Both, the oscillatory flow and drag force coefficient frequencies are similar as can be seen in Fig. 5. It is possible to identify this behavior in all the evaluated Reynolds in this work.

The variation of drag force coefficient as a function of Reynolds number is presented in Fig. 6. When the Reynolds number increases the mean drag coefficients decreases which, for previous studies, is an expected behavior (e.g. [32]). 


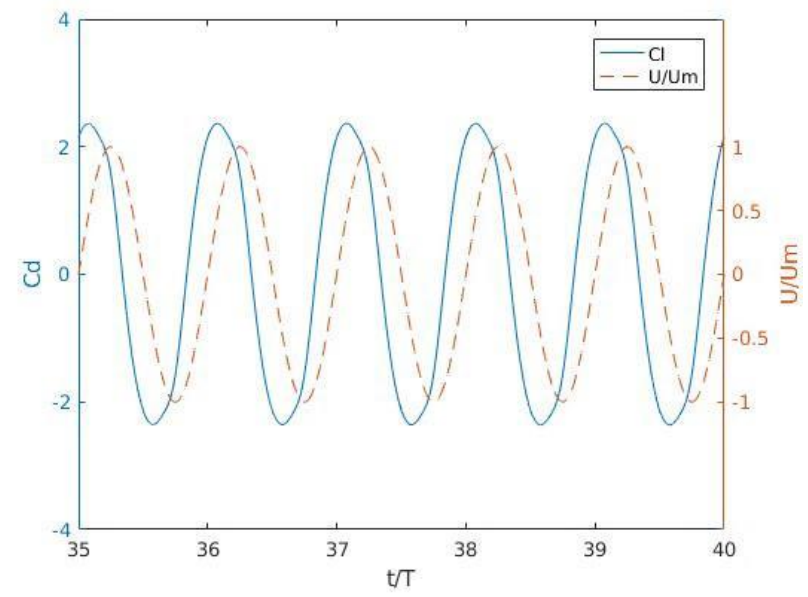

(a)

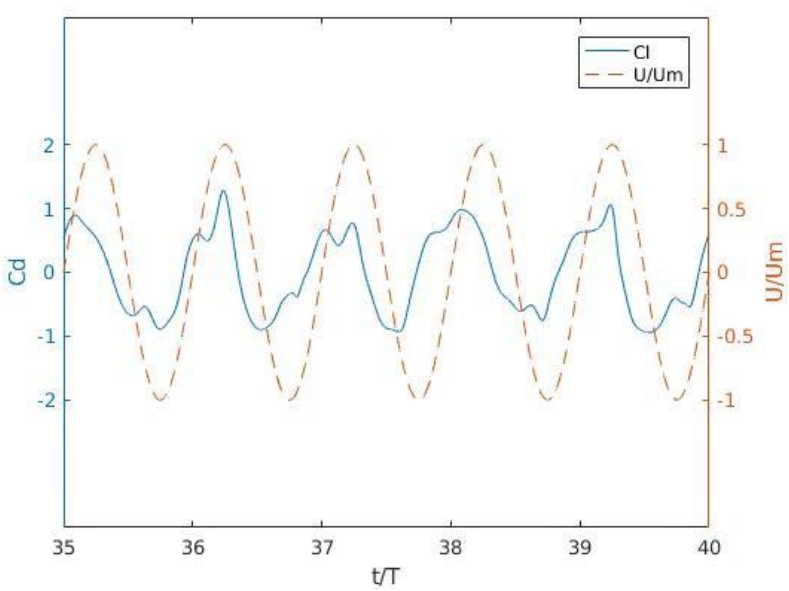

(b)

Fig. 5. Drag force coefficient for (a) $R e=200$ and (b) $R e=1000$

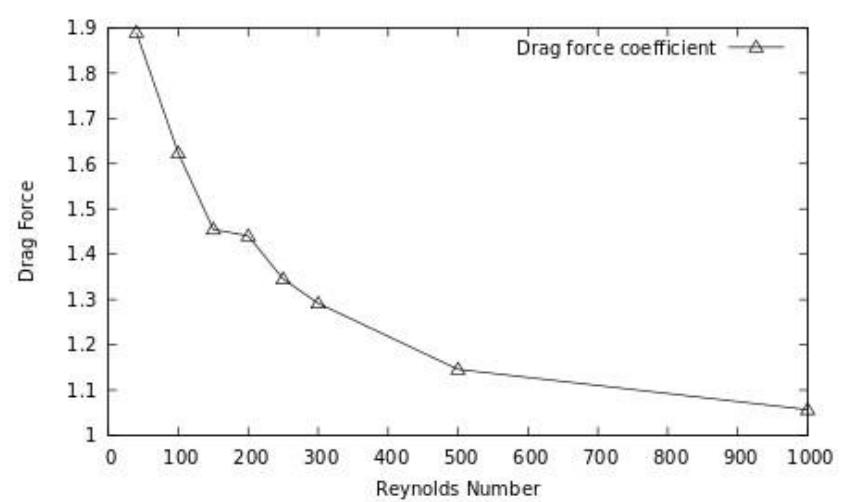

Fig. 6. Variation of drag force coefficient with Reynolds number for fluid flow around a circular cylinder.

Lift force coefficients for Reynolds 200 and 1000 are visualized in Fig. 7. Two positive and two negative peaks along the time history of lift coefficient for each period of oscillating flow are identified, meaning that the lift force frequency is twice the oscillating fluid frecuency. Sometimes is posible to observe up to 3 positive and negative peaks of lift force coefficient per oscillating period. The pressure distribution is not symmetric in the flow direction because the vortex shedding are not formed at the same time. Thus, the lowest Reynolds numbers presents less variation in amplitude and frequency parameters. Conversely, higher Reynolds showed significant variations, especially in fluctuation amplitude (Seeing Fig. 7).

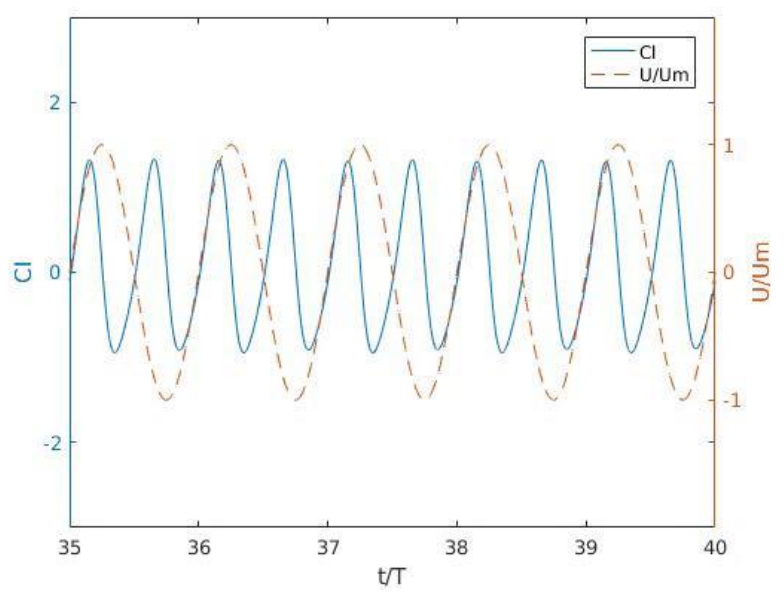

(a)

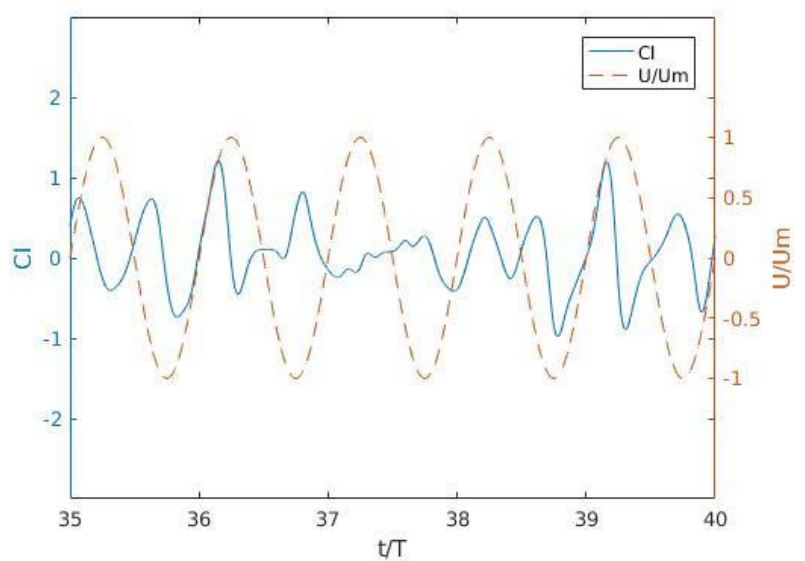

(b)

Fig. 7. (a) Lift force coefficient for $R e=200$ and (b) $R e=1000$

\section{B. Oscillating flow analysis}

The flow over a circular cylinder for different Reynolds values are simulated. The Fig. 8 to 15 show behaviors in differents times for cases when $R e$ ranges are between 40 and 1000. It is possible to notice that vortices remains with the acceleration and deceleration of flow. Fig. 8 presents a fixed pair of vortices in the wake. The vortices are symetric about the center line of the wake, which fits the Williamson regimen A description [5]. When the sinusoidal velocity is positive, two vortices are formed as shown in Fig. 8(a). The flow change its direcction in Fig. 8(b) and two new vortices developed in the opposite direction. Four vortices persist during a half vortex shedding period along the time, one pair for each direction. This is because the low sinusoidal flow velocity remains attached to the cylinder, as shown in Fig. 8(d).

Instability develops when Reynolds value is incremented as shown in Fig. 9(a). Two vortices are developed in the direction flow, describing a symmetrical V-pattern regimen at the cross- 
flow direction. Here, the last two vortices from the past cycle persist until the flow change of direction. In Fig. 9(b) the vortices move in opposite direction describing the same pattern. Again, the last two vortices from Fig. 9(a) persists. Fig. 9(c)(d) represent the second half of cycle equal to the first. About three pair of vortices persists during a half of vortex shedding period. This case goes according to the Fig. 1 by Tatsuno \& Bearman [13], regimen D behavior.

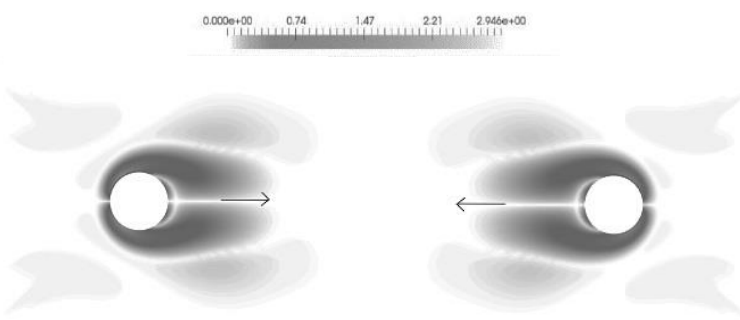

(a)

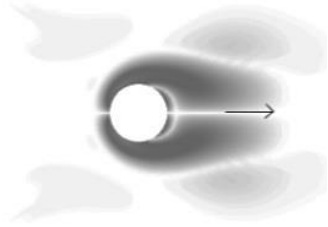

(c)

Fig. 8. Vorticity profile for $\mathrm{KC}=7.9$ and $R e=40$ at differents times illustraing a symmetric pattern (a) $t=80,62$, (b) at $t=81,14 \mathrm{~T}$, (c) at $\mathrm{t}=81,66 \mathrm{~T}$, and (d) at $\mathrm{t}=82,18 \mathrm{~T}$. Arrows indicate the vortices convected directions.

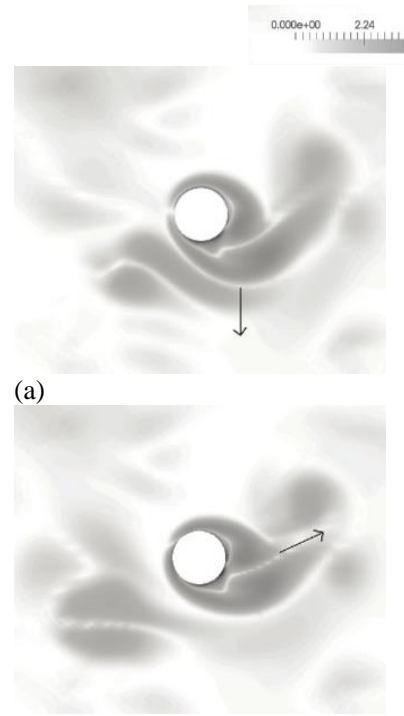

(c)

(b)

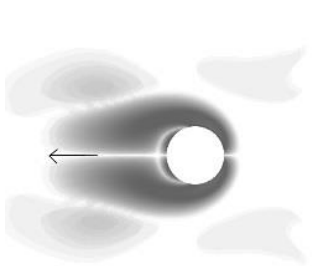

(d)
When Reynolds value increase $(R e>100)$, positive (anticlockwise) and negative (clockwise) vortex stars to shedding around the cylinder due to the oscillating flow. The V-pattern symmetrical regimen persists in $R e=150$ case but with intermittently changes as shown Fig. 10. Fig. 10(a) for example, describes a transverse street because the vortex moves in cross-flow direction. In the opposite direction, Fig. 10(b)(d) present an oblique street. Although V-pattern is present in Fig. 10 (c), the predominant vortex tends to move transversally in negative direction. For this Reynolds value, is

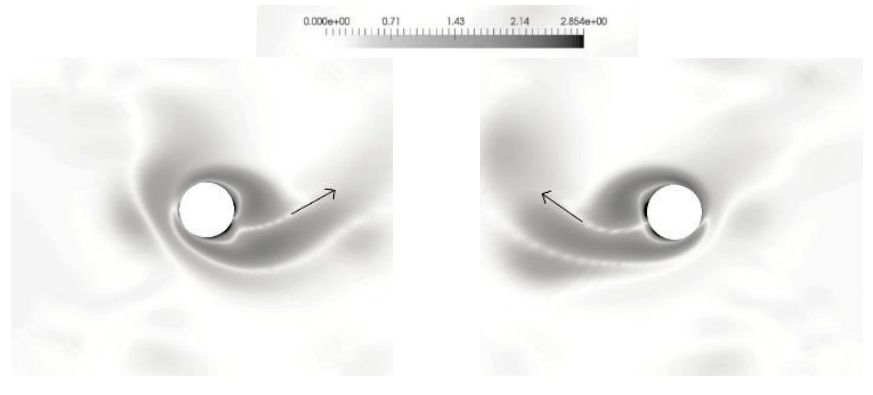

(a)

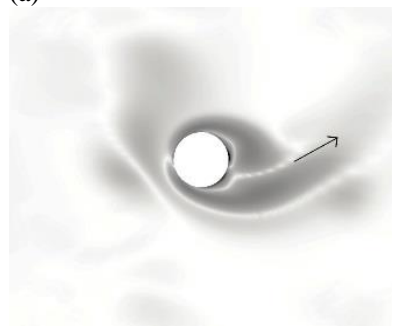

(c)

(b)

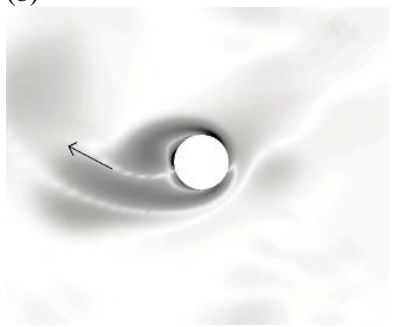

(d)

Fig. 9. Vorticity profile for $\mathrm{KC}=7.9$ and $R e=100$ at differents times illustraing a V-pattern (a) $\mathrm{t}=100.23 \mathrm{~T}$, (b) at $\mathrm{t}=100,73 \mathrm{~T}$, (c) at $\mathrm{t}=101.22 \mathrm{~T}$, and (d) at $\mathrm{t}=101,71 \mathrm{~T}$. Arrows indicate the vortices convected directions

more evident the persistent pair of vortices from the last phase.

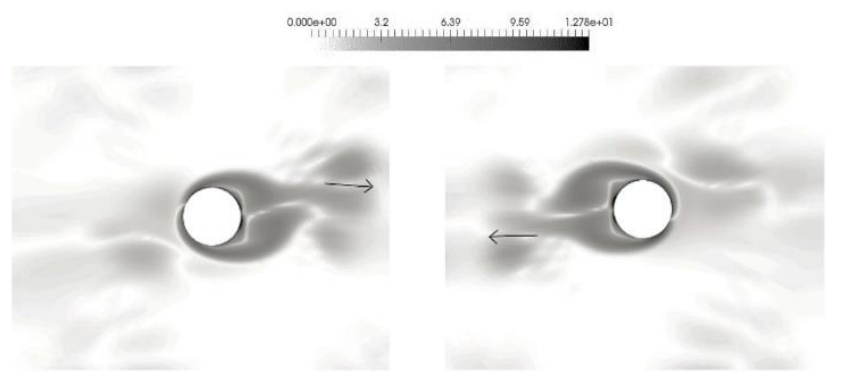

(a)

(b)

(c)

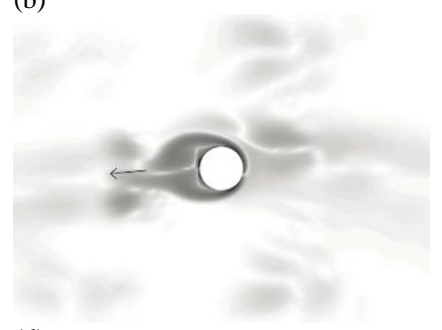

(d)

Fig. 11. Vorticity profile for $\mathrm{KC}=7.9$ and $R e=200$ at differents times illustraing a double pair regimen (a) $\mathrm{t}=90,39 \mathrm{~T}$, (b) at $\mathrm{t}=90,88 \mathrm{~T}$, (c) at $\mathrm{t}=91,38 \mathrm{~T}$, and $(\mathrm{d})$ at $\mathrm{t}=91,87 \mathrm{~T}$. Arrows indicate the vortices convected directions.
Fig. 10. Vorticity profile for $\mathrm{KC}=7.9$ and $R e=150$ at different times illustraing a double pair regimen (a) $\mathrm{t}=76,47 \mathrm{~T}$, (b) at $\mathrm{t}=76,95 \mathrm{~T}$, (c) at $\mathrm{t}=77,44 \mathrm{~T}$, and (d) at $\mathrm{t}=77,93 \mathrm{~T}$. Arrows indicate the vortices convected directions 
Between three and four pairs of vortices are possible to see in each half of vortex shedding period for this Reynolds value.

For high Reynolds values, more vortices endure in a cycle. Vorticity field for the case of $R e=200$ are shown in Fig. 11 . Three pair of vortices can visualized in Fig. 11 (a), one pair from the present half of cycle and the others from the past cycle. On the rigth cylinder, two pair of vortices are sheddding. This pattern is known as doble pair regimen of Williamson [5]. The same situation is shown in Fig. 11(b)-(c), where two pair of vortices are presented in the direction of flow along the time. Is important to note that V-pattern are stabilized in this Reynolds value, where the vortices developed in a symetric way on both sides of the cylinder.

The regimen $\mathrm{F}$ is evident in Fig. 12 for $R e=250$ because the same two pairs of vortices are shedding, and a traverse vortex street is formed around the cylinder in an oblique street. About six vortices around the cylinder are visualized every half of vortex shedding period, as can be seen in Fig. 12(a)-(b).

With the increase in the Reynolds value, a regimen instability appears during the time history. Fig. 13(a) presents a V-pattern characteristic of regimen F at Reynolds 300. Later, a drastic change is observed in Fig. 13(b), where a transverse street is appearing. At 67,91T V-pattern symmetrical is visualized in right-left direction. Finally, an oblique street is present at $71,87 \mathrm{~T}$. This Reynolds value is classified by Williamson [5] as regimen $\mathrm{G}$, but transverse street is not the most persistent behavior. The pattern is chaotic with four different behaviors visualized.

Vorticity field for $R e=500$ can visualized in Fig. 14. Two well-defined vortices are highlighted in Fig. 14(a) with another vortex lags from past cycles. Here, a V-patter is visible. Fig. 14(b) shows five vortices around the cylinder. Two of them

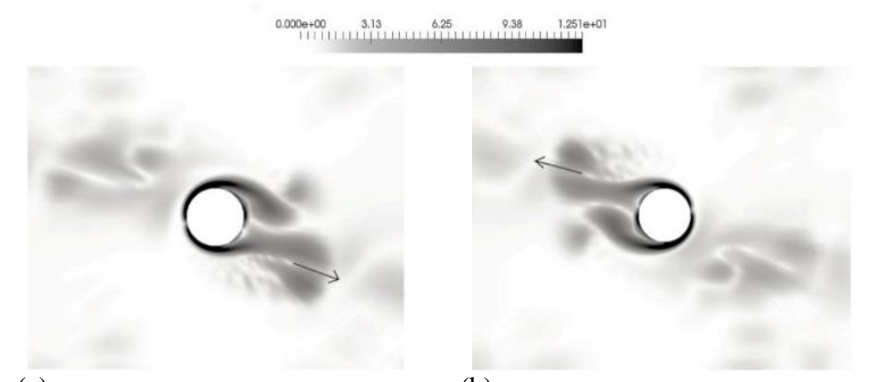

(a)

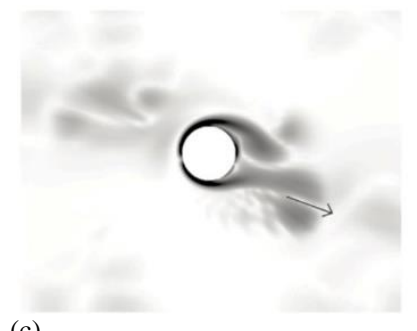

(b)

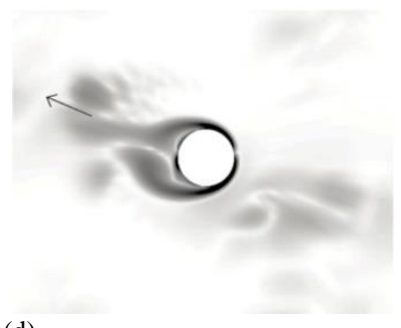

(d)

Fig. 12. Vorticity profile for $\mathrm{KC}=7.9$ and $R e=250$ at differents times illustraing a double pair regimen (a) $\mathrm{t}=60,27 \mathrm{~T}$, (b) at $\mathrm{t}=60,80 \mathrm{~T}$, (c) at $t=61,29 T$, and $d$ ) at $t=61,84 T$. Arrows indicate the vortices convected directions from the present cycle. In this case, an oblique street is visualized. A transverse pattern is representative for Fig. 14(c), where about two pair of vortices can be identified. Six vortices going in right-left direction, presenting a V-pattern symmetrical in Fig. 14(d), which is a characteristic of regimen D. The vortex structure of $R e=500$ case corresponds to mode $\mathrm{G}$ where transverse Street is characterized. Nevertheless, this is not a dominant pattern for the case.

Fig. 15(a) shows two pair of vortices detaching from the cylinder, two vortices developed in the past cicle and the traces of others past vortices shedded. A transversal street characterized is visualized at 90,48T. In Fig. 15b) three pair of vortices are presented, two of them from the past cycle. A Vpattern around the transverse axis is visualized here. The flow goes from the right to the left (negative direction) in Fig. 15(c) where about five vortices are present. The main two vortices are shed describing an oblique street at 96,83T. In the same direction, Fig. 15(d) shown a V-pattern symmetrical in oblique direction.

Is important to highlight in a half cycle between 9 and 10 vortices staying around the cylinder, a behavior related to the regime $\mathrm{G}$ of Williamson [5] classification. However, a chaotic slant vortex street is developed left and right of the cylinder without persistent vortex pattern observed along the time for this Reynolds value.

\section{Temporal force analysis}

The semi-empirical equation (3) estimate the in-line force on a cylinder divided in two forces: 1) The drag force, proportional to the flow instantaneous velocity square and 2) the inertial flow coupled with the local flow acceleration [31]. The drag force coefficient $C_{d}$ and the inertial force coefficient $C_{m}$ can be

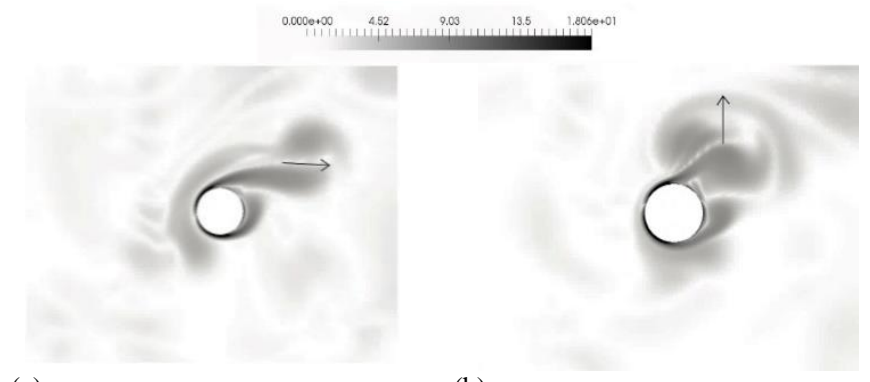

(a)

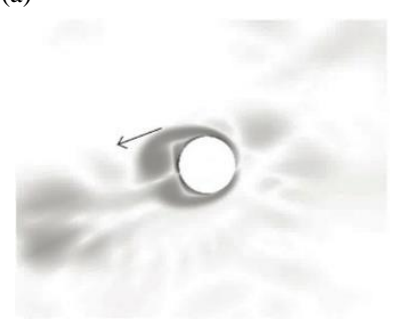

(c) (b)

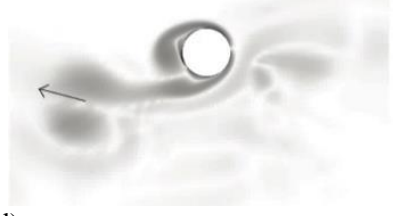

(d)
Fig. 13. Vorticity profile for $\mathrm{KC}=7.9$ and $\mathrm{Re} 300$ at differents times illustraing a V-pattern a) $\mathrm{t}=61,48 \mathrm{~T}$, transverse street b) at $\mathrm{t}=63,37 \mathrm{~T}, \mathrm{~V}$-pattern symetrical c) at $\mathrm{t}=67,91 \mathrm{~T}$, and oblique street $\mathrm{d}$ ) at $\mathrm{t}=71,87 \mathrm{~T}$. Arrows indicate the vortices covected directions. 
obtained by last square fifting on the time history of $F_{o s c}$, or calculated using the equations below [33].

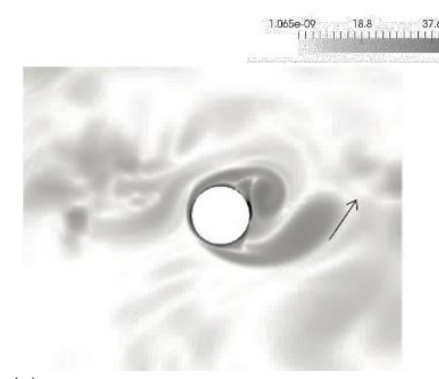

(a)

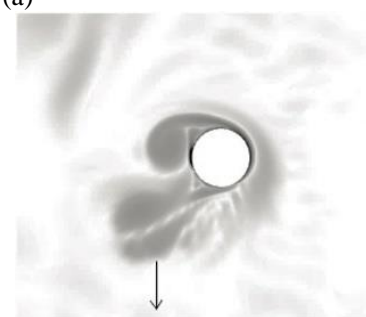

(c)

(d)

Fig. 14. Vorticity profile for $\mathrm{KC}=7.9$ and $\mathrm{Re} 500$ at differents times illustraing a $\mathrm{V}$-pattern a) $\mathrm{t}=61,48 \mathrm{~T}$, oblique street b) at $\mathrm{t}=63,37 \mathrm{~T}$, transverse pattern c) at $t=67,91 \mathrm{~T}$, and $\mathrm{V}$-pattern symetrical d) at $\mathrm{t}=71,87 \mathrm{~T}$. Arrows indicate the vortices covected directions.

$$
\begin{aligned}
& C_{d}=\frac{3}{4} \int_{0}^{2 \pi} \frac{F_{D} \sin \theta}{\rho D U_{1}^{2}} d \theta=\frac{3}{8} \int_{0}^{2 \pi} C_{D} \sin \theta d \theta \\
& C_{i}=\frac{2 U_{1} T_{f}}{\pi^{3} D} \int_{0}^{2 \pi} \frac{F_{D} \cos \theta}{\rho D U_{1}^{2}} d \theta=\frac{U_{1} T_{f}}{\pi^{3} D} \int_{0}^{2 \pi} C_{D} \cos \theta d \theta
\end{aligned}
$$

Where, $C_{D}$ represents the mean drag coefficient.

According to $\mathrm{Cao}$ and $\mathrm{Li}$ [31], the time history of drag force can be acceptably approximated by Morrison's equation. Using the same equations is possible to obtain the cross-flow force. Fig. 16 shows an interval of in-line and cross-flow forces for every Reynolds value studied.

The drag and the inertial forces share a direct relation with the vortex behavior as shown in Fig. 16. A uniform in-line force with almost constant frequency and period can visualized in Fig. 16(a). As presented before, this regimen A does not exhibits vortex detachment, but it does shows a vortex formation totally symetric in the direction of the flow. This is why in-line force predominates and the trasnverse force is almost null.

A representative regimen D is showed in Fig. 16(b), where the V-pattern symmetrical starts to dominate and the cross-flow force becomes important. The symmetric pattern becomes predominant when the cross-flow force amplitude reduces. The fluctuation force classify this case of Reynolds value in a symmetric regime group. The $R e=150$ case present and amplitude instability due the irregular vortex shedding in Fig. 16(c). After a while, the fluctuations tends to become regular and the in-line force is stabilizes. Here regimen $\mathrm{E}$ is predominant with intermitently changes of direction, related with the fluctuating amplitude in-line force because the action of cross-flow force. When cross-flow force present a peak, vorticity pattern tends to be transversal street as can be idenified in Fig. 10(a) at 76,47T.

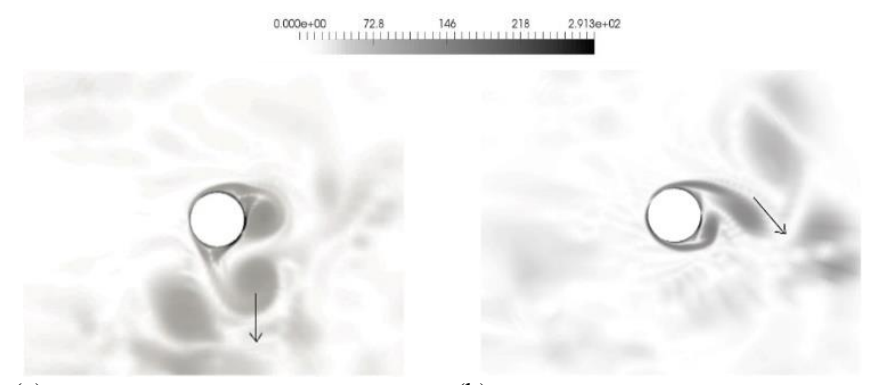

(a)

(b)

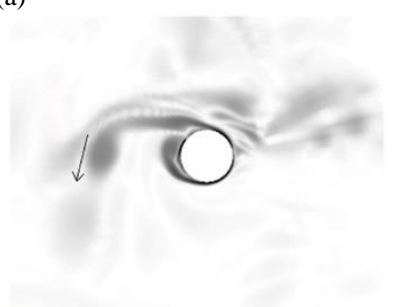

(c)

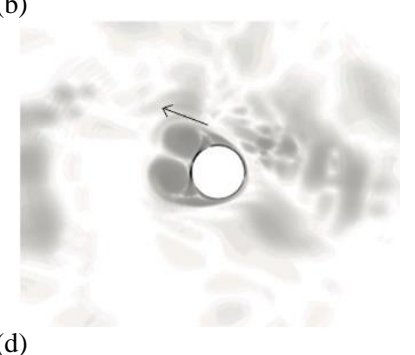

(d)

Fig. 15. Vorticity profile for $\mathrm{KC}=7.9$ and Re 1000 at differents times illustraing a transverse pattern a) $\mathrm{t}=90,48 \mathrm{~T}, \mathrm{~V}$-ppattern b) at $\mathrm{t}=91,27 \mathrm{~T}$, oblique street c) at $\mathrm{t}=96,83 \mathrm{~T}$, and $\mathrm{V}$-pattern symetrical in oblique direction $\mathrm{d}$ ) at $\mathrm{t}=97,95 \mathrm{~T}$. Arrows indicate the vortices covected directions.

For $R e=200$, an amplitude stability is presented and persist at the time (Fig. 16(d)). In the same way, the $R e=250$ present a regular fluctuation force (Fig. 16(e)). Also, cross-flow force present uniform behavior for both Reynolds (200 and 250). As mentioned previously, Reynolds case 200 and 250 are dominated by regimen $\mathrm{F}$. In-line force for $R e=200$ tends to be more stable in comparison with $R e=250$ which means the first one present vortex shedding more

symmetrical about the cross-flow axis while the second one tends to be more transversal. In this way, the proximity to the transition range is a bit evident for $R e=250$.

For case of Reynolds 300, 500 and 1000, in-line and crossflow forces are chaotic and strong peaks appear (see Fig. $16(\mathrm{f})(\mathrm{g})$ and $(\mathrm{h}))$. A chaotic behavior is observed here because there are no persistent vortex pattern. Sometimes, the dominant harmonic for the case of $R e=1000$ are three times the frequency of oscillating fluid flow, but predominates two times the oscillating frequency. On the other hand, flow regime is dominated by the viscous drag component in all the cases.

\section{Spectral analysis}

Several oscillating fluid flow frequencies peaks that are integral times the vortex oscillating frequency, are illustrated in Fig. 17 and Fig. 18. These figures were taking from time history of drag force and lift force coefficients respectively, using Fast Fourier Transform (FFT). The oscillating frequencies are graphed with the magnitude of the Fourier Transform, using the main peak as indicated Williamson [5]. Spetral analysis of drag force is shown in Fig. 17 with several peaks at frequencies. The main frequency are always the oscillating frequency and the 


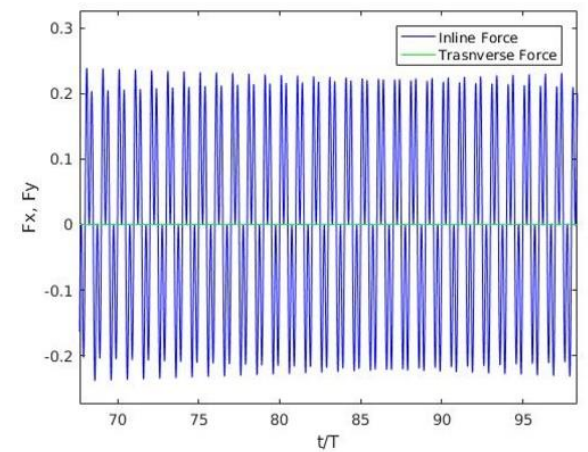

(a)

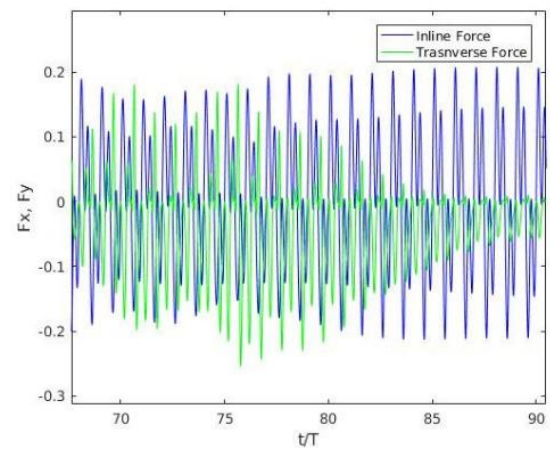

(c)

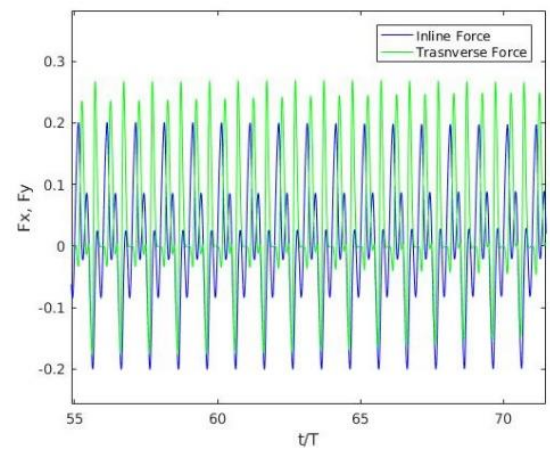

(e)

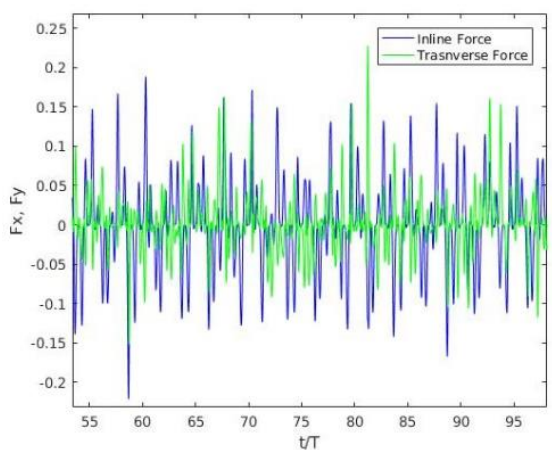

(g)

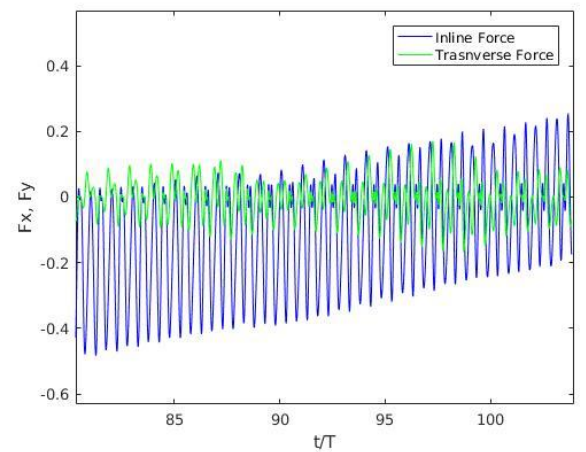

(b)

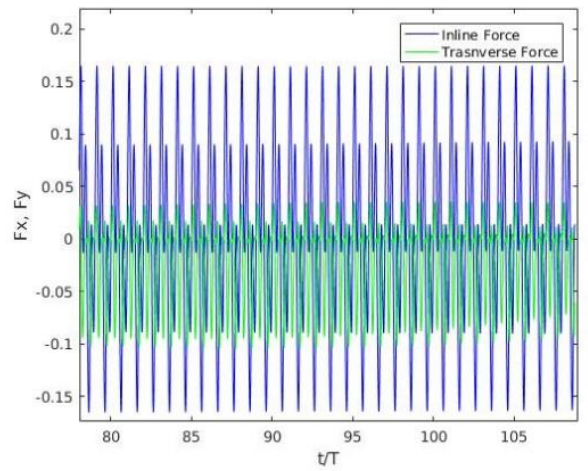

(d)

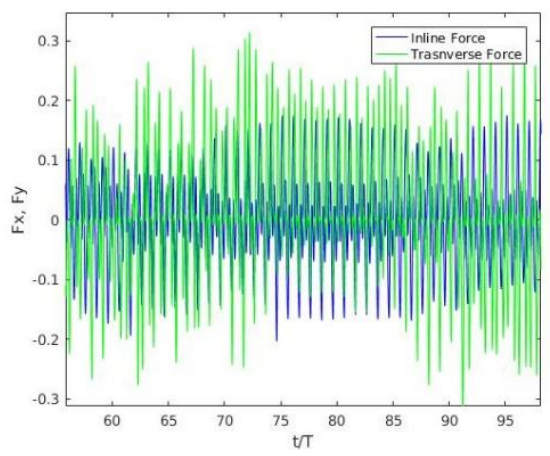

(f)

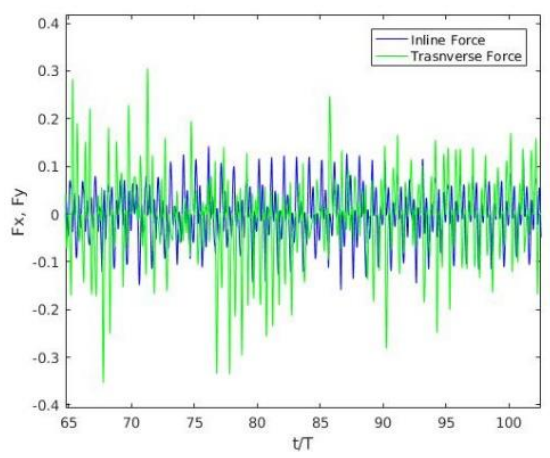

(h)

Fig. 16. In-line and cross-flow forces for a) $\operatorname{Re} 40$, b) $\operatorname{Re} 100$, c) $\operatorname{Re} 150$, d) $\operatorname{Re} 200$, e) $\operatorname{Re} 250$, f) $\operatorname{Re} 300$, g) $\operatorname{Re} 500$ and h) $\operatorname{Re} 1000$.

other peaks has an increment factor, namely $3 f_{0}, 5 f_{0}, 7 f_{0}$ and in that way forward (see Fig. 17(a)(b)(c)), for regimes A, D, E and F. Besides of the main frequency and the $3 f_{0}$ peak, other frequencies peaks without multiple of $f_{0}$ appear in regimen $\mathrm{G}$.
It is possible to note, the oscillating frequencies for $R e<200$ (see Fig. 4) are twice the main frequency of lift coefficient. As 


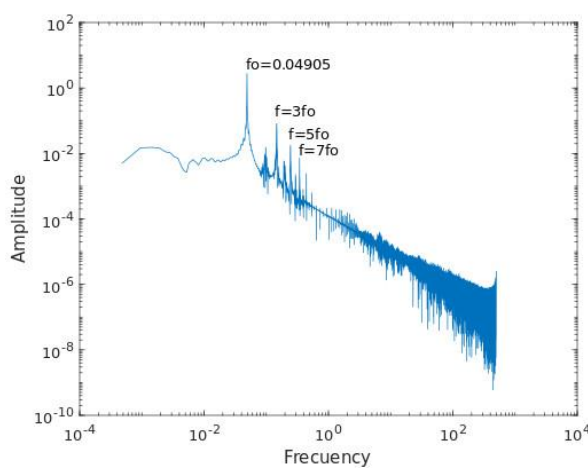

(a)

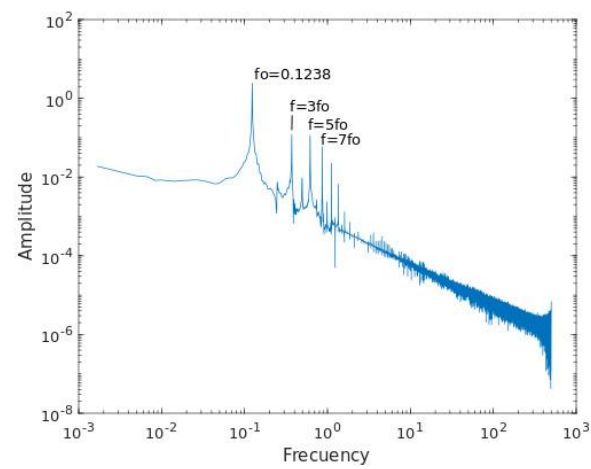

(c)

Fig. 17. Spetral analysis of drag force coefficient at a) Re 100, b) Re 150, c) Re 250, d) Re 1000. shown in Fig. 18(a)(b), for regimes A and E respectively, the main frequencies occur with an increment of $2 f_{0}$.

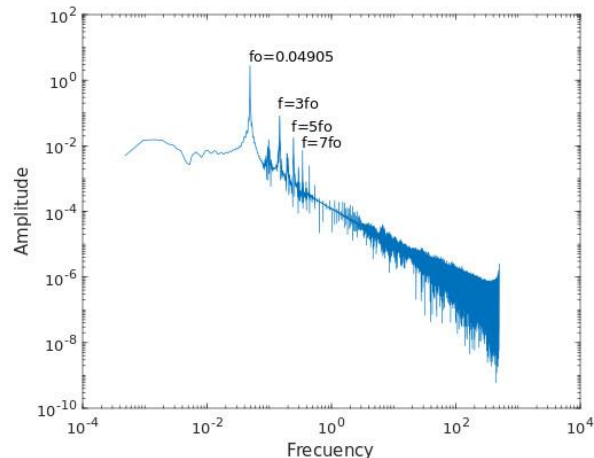

(a)

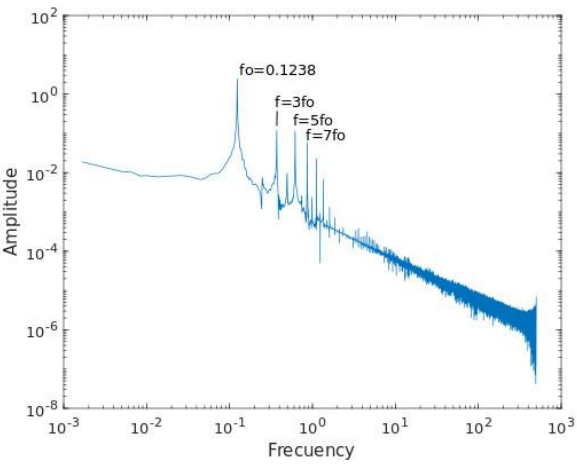

(c)

Fig. 17. Spetral analysis of drag force coefficient at a) Re 100, b) $\operatorname{Re} 150$, c) $\operatorname{Re} 250$, d) $\operatorname{Re} 1000$. (b)
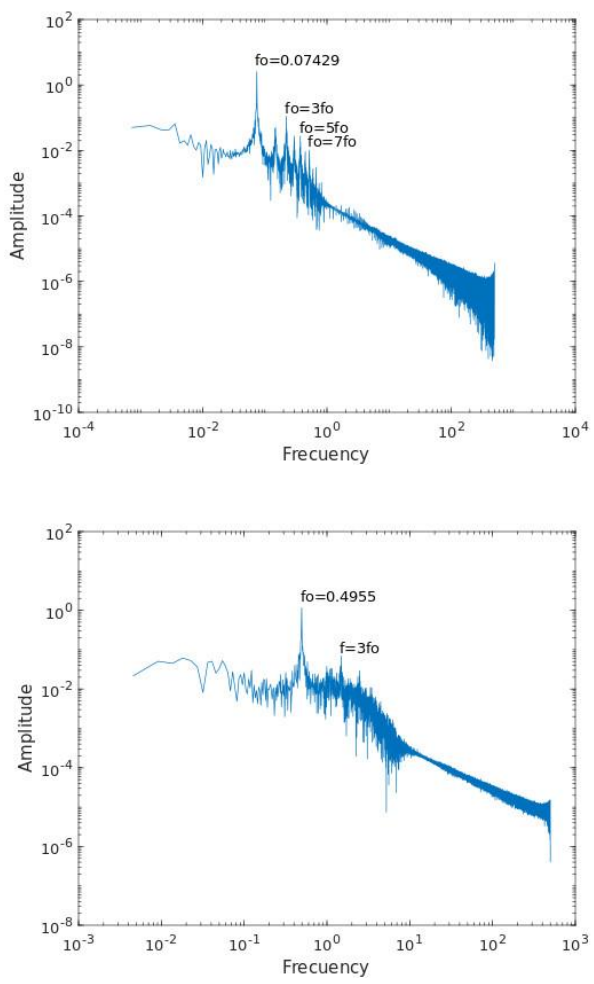

(d) 
Otherwise, the dominant frequency for regimen $\mathrm{F}$ (Fig. 18(c)) is three times the oscillating frequency. In this case, the case of Reynold value 250 presents main frequency at $3 f_{0}$ and the increment is about $1 f_{0}$ in the other peaks of frequencies. The same behavior for these regimens is shown by Duclercq et al. [16]. Again, for Reynolds values higher than 300 the oscillating frequencies are two times the main frequency of lift coefficient. Note that the main frequency in Fig. 18(d), is presented around of $2 f_{0}$. Them appear other frequencies peaks without a clear multiple of $f_{0}$ and strong fluctuations is observed, according to Fig. 16(f)-(h). Williamson [5] concluded that in an oscillating flow, the dominant frequency of lift force is equal to one plus the number of vortices shedding in a half period, which is evidenced in the regimes A, D and F. However, for regimen G this condition is not fulfilled as proved in this study.

\section{E. Experimental validation}

Riveros et al. [24] conducted a series of forced oscillation experiments for flexible risers where a 20-meter riser model was tested for different values of $R e$ and $K C$ numbers; their experimental model case 1 has the same diameter as $R e(1000)$ and $K C(7,9)$ numbers presented here in Fig. 15. Although good agreement was reported by Riveros et al. [24], it is still possible to observe some deviations between the simulation results and experimental data in the main cross-flow frequency. The model presented in this paper, as shown in Fig. 18(d), overcomes this difficulty providing a value of the dominant cross-flow frequency in good agreement with the experimental value of 1 $\mathrm{Hz}$ presented by Riveros et al. [24]. Likewise, the dominant inline-flow frequency presented in the experimental model by Riveros et al. [24] is $4,9 \mathrm{~Hz}$, the same visualized in Fig. 17(d) using the numerical model.

\section{SUMMARY}

A numerical based approach for predicting the response cylindrical system considering low mass damping ratio and under oscillatory flow was presented in this paper. Numerical simulations of showed a inverse relationship between the Reynolds number and the mean drag coefficients, an expected behavior [24], also demostrated that the peaks shape variation is related with a pressure distribution asymmetry in the flow direction, due to asinchrony in the vortex shedding. Thus, the lowest Reynolds number, the less variation in amplitude and frequency parameters and conversely, the higher Reynolds numbers produces significant variations, especially in fluctuation amplitude.

At Reynolds value 40, four vortices, one pair for each direction, persist during a half vortex shedding period because the low sinusoidal flow velocity remains attached to the cylinder. In this way, a uniform in-line force with almost constant frequency and period is present. This behaviour have a good agreement to the Williamson regimen with vortex symmetric formation in the flow direction which explains why the in-line force predominates and the cross-flow force is almost null. Instability develops when Reynolds value is incremented to $R_{e}=100$. Two vortices describing a transverse symmetrical V-pattern regimen develops in the flow direction, and two vortices from the past cycle persist until the flow reverses. Three pair of vortices persists during a half of vortex shedding period. This is conforms to Tatsuno \& Bearman regimen $\mathrm{D}$ behavior, where a symmetrical V-pattern began to develop and the cross-flow force becomes important.

As the Reynolds value increases $\left(R_{e}>100\right)$, positive (anticlockwise) and negative (clockwise) vortex began to shed from the cylinder due to the oscillating flow, and more vortex endures a cycle. The V-pattern symmetrical regimen persists in the $R_{e}=150$ case because changes intermittently from a transverse street to oblique street vortex. The persistence of the vortex pairs from the last phase is longer and between three and four pairs of vortices are visible in each vortex shedding half period. An amplitude instability is present due irregular vortex shedding, after a while, the fluctuations becomes regular and the in-line force stabilizes. Here regimen $\mathrm{E}$ is predominant with intermittently changes of direction, related with the fluctuating amplitude in-line force because the action of cross-flow force, this conforms to Tatsuno \& Bearman.

The vorticity field for the case of $R_{e}=200$ has three pair of vortex one pair from the present half of cycle and two from the past cycle, a Williamson double pair regimen develops and the V-pattern are stabilized. For $R_{e}=250$ two pair of vortices are shedding and a traverse vortex street is formed around the cylinder in an oblique street. About six vortex around the cylinder can be seen every vortex shedding half period. Both Reynolds values show a regular fluctuation force and also, the cross-flow force present uniform behavior. In-line force for $R_{e}=200$ tends to be more stable in comparison with $R_{e}=$ 250 , so $R_{e}=200$ shows vortex shedding more symmetrical about the cross-flow axis while the second one tends to be more transversal. In this way, the proximity to the transition range is evident for $R_{e}=250$. Both cases are conform to Tatsuno \& Bearman regimen $\mathrm{F}$ behavior.

Regimen instability appears as the Reynolds value increases. For Reynolds 300, a regimen F V-pattern characteristic is developed, however drastic changes are observed, where a transverse street began to appear and later an oblique street is developed. This Reynolds value is classified by Williamson [5] as regimen $\mathrm{G}$, but transverse street is not the most persistent behavior. The pattern is considered chaotic (but may be transitional F-to-G) and four different behaviors were visualized.

Two well-defined and several others vortex lagging from past cycles are visible at $R_{e}=500$. A V-pattern is developed with transformations to oblique street to transverse pattern. The vortex structure of $R e=500$ case was classified by Tatsuno and Bearman as regimen $G$ where transverse street is characteristic, however, there is not dominant pattern for this case. About seven vortex around the cylinder can be seen every vortex shedding half period.

Two pair of vortices detaching in an oblique street from the cylinder, two vortices remaining form the past cicle and traces of several others vortices shredded in previous cycles are visible 
at $R_{e}=1000$. Characteristic transversal street and a V-pattern around the cross-flow axis is evident. At each half cycle, between 9 and 10 vortices stay around the cylinder, a behaviour typical of Williamson regime G, however, a chaotic slant vortex street is developed left and right of the cylinder without persistent vortex pattern observed along the time. About nine vortex around the cylinder can be seen every vortex shedding half period

For the Reynolds cases 300, 500 and 1000, in-line and crossflow forces are chaotic and strong peaks appear. This chaotic behavior is present because there are no persistent vortex patterns. The dominant harmonic for the case of $R e=1000$ sometimes is three times higher than the oscillating fluid flow frequency, but two times the oscillating frequency. The flow regime is dominated by the viscous drag component in all these cases. Finally, the numerical results presented in this paper for the dominant in-line and cross-flow frequency shows good agreement with experimental results provided by Riveros $e t \mathrm{al}$. [24].

\section{ACKNOWLEDGEMENTS}

This work is part of the Master Thesis of MC ValenciaCardenas with MODESIS Group and under her 'Numerical modelling of the Ocean' research line at GEOc.

\section{REFERENCIAS}

[1] S. Chakrabarti, «The Theory and Practice of Hydrodynamics an Vibration,» World Scientific Publishing., vol. 20, 2002. DOI: $10.1142 / 4936$

[2] Thorsen, S. Saevick and C. Larsen, «Time domine simulation of vortex-induced vibrations in stationary and oscillating flows,» Journal of Fluids and Structures, vol. 61, pp. 1-19, 2016. DOI: 10.1016/j.jfluidstructs.2015.11.006

[3] B. Fu and D. Wan, «Numerical study of vibrations of a vertical tension riser excited at the top and the end,» Journal of Ocean Engineering ans Science, 2017. DOI: 10.1016/j.joes.2017.09.001

[4] P. Bearman, M. Downie, J. Graham and E. Obasaju, «Forces on cylinders in viscous oscillatory flow at low Keulegan-Carpenter numbers. Journal,» Journal of Fluid Mechanics, vol. 154, p. 337-356, 1985. DOI: $10.1017 /$ S0022112085001562

[5] C. Williamson, «Sinusoidal flow relative to circular cylinders,» Journal of Fluid Mechanics, vol. 155, p. 141-174, 1985. DOI: 10.1017/S0022112085001756

[6] E. B. P. G. J. Obasaju, «A study of forces, circulation and vortex patterns around a circular cylinder in oscillatory flow,» Journal of Fluid Mechanics 196, vol. 196, p. 476-494, 1988 . DOI: 10.1017/S0022112088002782

[7] [7] P. Justesen, «A numerical study of oscillating flow around a circular cylinder,» Journal of Fluid Mechanics, vol. 222, p. 157-196, 1991. DOI: $10.1017 /$ S0022112091001040

[8] [8] H. An, L. Cheng and M. Zhao, «Steady streaming around a circular cylinder in an oscillatory flow,» Ocean Engineering, vol. 36, p. 10891097, 2009. DOI: 10.1016/j.oceaneng.2009.06.010
[9] H. An, L. Cheng and M. Zhao, «Steady streaming around a circular cylinder near a plane boundary due to oscillatory flow,» Journal of Hydraulic Engineering, vol. 137, p. 23-33, 2011. DOI: 10.1061/(ASCE)HY.1943-7900.0000258

[10] M. Zhao, K. Kaja, Y. Xiang and G. Yan, «Vortex-induced vibration (VIV) of a circular cylinder in combined steady and oscillatory flow,» Ocean Engineering, vol. 73, pp. 83-95, 2013. DOI: 10.1016/j.oceaneng.2013.08.006

[11] C. Williamson and R. Govardhan, «A brief review of recent results in vortex-induced vibration,» Journal of Wind Engineering and Industrial Aerodynamics, vol. 96, p. 713-735, 2008. DOI: 10.1016/j.jweia.2007.06.019

[12] R. Govardhan and C. Williamson, «Defining the 'modified Griffin plot in vortex-induced vibration: revealing the effect of Reynolds number using controlled damping,» Journal of Fluid Mechanics, vol. 561, pp. 147-180, 2006. DOI: 10.1017/S0022112006000310

[13] M. Tatsuno and P. Bearman, «A visual study of the flow around an oscillating circular cylinder at low Keulegan-Carpenter numbers and low Stokes numbers,» Journal of Fluids Mechanics, vol. 211, pp. 157182, 1990. DOI: $10.1017 /$ S0022112090001537

[14] T. Morse and C. Williamson, «Fluid forcing, wake modes, and transitions for a cylinder undergoing controlled oscillations,» Journal of Fluid and Structure, vol. 25, $\mathrm{n}^{\circ} 4$, pp. 697-712, 2009. DOI: https://doi.org/10.1016/j.jfluidstructs.2008.12.003

[15] J. Klamo, A. Leonard and A. Roshko, «On the maximum amplitude for a freely vibrating cylinder in crossflow,» Journal of Fluids and Structures, vol. 21, p. 429-434, 2005. DOI: 10.1016/j.jfluidstructs.2005.07.010

[16] M. Duclercq, D. Broc and O. Cadot, «Characterization of long time fluctuations of forces exerted on an oscillating circular cylinder at $\mathrm{KC}=10$,» Journal of Fluids and Structures, vol. 27, n 4, pp. 18-29, 2011. DOI: 10.1016/j.jfluidstructs.2011.01.004

[17] J. Lin and D. Rockwell, «Quantitative interpretation of vortices from a cylinder oscillating in quiescent fluid,» Experiments in Fluids, vol. 23, nº 2, pp. 99-104, 1997. DOI: $10.1007 / \mathrm{s} 003480050090$

[18] P. Anagnostopoulos and G. Iliadis, «Numerical study of the flow pattern and the in-line response of a flexible cylinder in an oscillating stream,» Journal of Fluids and Structures, vol. 12, pp. 225-258, 1998. DOI: $10.1006 /$ jfls.1997.0139

[19] G. Iliadis and P. Anagnostopoulos, «Viscous oscillatory flow around a circular cylinder at low Keulegan-Carpenter numbers and frequency parameters,» International Journal for Numerical Methods in Fluids, vol. 26, p. 403-442, 1998.

[20] H. Dutsch, F. Durst, S. Becker and H. Lienhart, «Low-Reynoldsnumber flow around an oscillating circular cylinder at low KeuleganCarpenter numbers,» Journal of Fluid Mechanics, vol 360, p. 249-271, 1998. DOI: 10.1017/S002211209800860X

[21] B. Uzunoglu, M. Tan and W. Price, «Low-Reynolds-number flow around an oscillating circular cylinder using a cell viscous boundary element method,» International Journal for Numerical Methods in Engineering, vol. 50, p. 2317-2338, 2001. DOI: https://doi.org/10.1002/nme.122

[22] E. Guilmineau and P. Queutey, «A numerical simulation of vortex shedding from an oscillatory circular cylinder,» Journal of Fluids and Structures, vol. 16, $\mathrm{n}^{\mathrm{o}} 6, \quad \mathrm{p}$. 773-794, 2002. DOI: 10.1006/jfls.2002.0449

[23] D. Nehari, V. Armenio and F. Ballio, «Three-dimensional analysis of the unidirectional oscillatory flow around a circular cylinder at low Keulegan- Carpenter and beta numbers,» Journal of Fluid Mechanics, vol. 520, p. 157-186, 2004. DOI: 10.1017/S002211200400134X

[24] C. Riveros, T. Utsunomiya, K. Maeda and K. Itoh, «Response prediction of long flexible risers subject to forced,» Journal of Marine and Science Technology, vol. 15, pp. 44-53, 2010. DOI: 10.1007/s00773-009-0070-5 
[25] C. J. Greenshields, OpenFOAM User Guide, OpenFOAM Fundation, 2017. Available: https://cfd.direct/openfoam/user-guide/

[26] J. Morison, M. O’Brien, J. Johnson and S. Schaaf, «The force exerted by surface waves on piles,» Journal of Petroleum Technology, vol. 189, p. 149-154., 1950. DOI: 10.2118/950149-G

[27] S. Étienne and D. Pelletier, «The low Reynolds number limit of vortexinduced vibrations,» Journal of Fluids and Structures, vol. 31, pp. 1829, 2012. DOI: 10.1016/j.jfluidstructs.2012.02.006

[28] J. K. Tawekal, CFD simulation of the Flow over a 2-Dimensional Pipe and Vortex Induced Vibration of the Pipe with 1 Degree of Freedom, M.S. thesis, Faculty of Science and Technology, Univ. of Stavanger, Stavanger, Norway, 2015.

[29] Z. Pan, W. Cui and Q. Miao, «Numerical simulation of vortex-induced vibration of a circular cylinder at low mass-damping using RANS code,» Journal of Fluids and Structures, vol. 23, pp. 23-32, 2007. DOI: 10.1016/j.jfluidstructs.2006.07.007

[30] S. Cao, S. Ozono, Y. Tamura, Y. Ge and H. Kikugawa, «Numerical simulation of Reynolds number effects on velocity shear flow around a circular cylinder,» Journal of Fluids and Structures, vol. 26, p. 685702, 2010. DOI: 10.1016/j.jfluidstructs.2010.03.003

[31] S. Cao and M. Li, «Numerical study of flow over a circular cylinder in oscillatory flows with zero-mean and non-zero-mean velocities,» Journal of Wind Engineering and Industrial Aerodynamics, vol. 144, pp. 42-52, 2015. DOI: 10.1016/j.jweia.2015.04.007

[32] T. Sarpkaya, «In-line and Transverse Forces on Smooth and Sandroughened Cylinders in Oscillatory Flow at High Reynolds Numbers,» National Science Foundation, 1976.

[33] G. C. L. Keulegan, «Forces on cylinders and plates in an oscillating fluid,» Journal of Research of the National Bureau of Standards, vol. 60, pp. 423-440, 60, 1958.

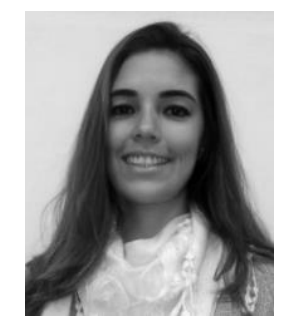

Maria Catalina Valencia-Cárdenas, currently is Assistant Professor at the Engineering School, Universidad de Antioquia (Colombia). She earned her Bachelor of Engineering in Civil Engineering in 2011 and her Master of Engineering in 2018 with a work in fluid dynamics; both degrees were awarded by the Universidad de Antioquia.

In 2012, she began to work as professor at the Universidad de Antioquia Marine Sciences Campus (Turbo, Colombia) and later she moved to the Engineering School at Carmen de Viboral Campus of the same university. Her research interests include structures, fluid mechanics, fluid dynamics and numerical models.

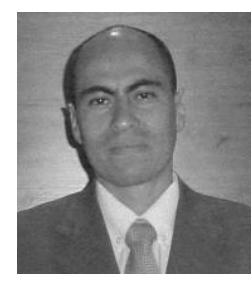

C.A. Riveros-Jerez, received his BSc. Eng in Civil Engineering in 1998 from the Universidad Industrial de Santander (UIS), Bucaramanga, Colombia. He obtained his M.Eng. in 2004 from the University of Tokyo and his Dr.Eng. in 2008 from Kyoto University. In 2005, Dr. Riveros began to work as an assistant professor in the Universidad de Antioquia, Medellín, Colombia. His currently associate professor. His research interests include structural dynamics, fluid dynamics, bridge engineering, concrete structures, structural health monitoring, and earthquake engineering. 